\title{
From the Editor-in-Chief
}

Once again in my career, I find myself both terrified and excited. I suppose some people ride roller coasters or take up skydiving to get this effect. For me, however, this sense of the anticipation comes from taking over the editorship of this journal. I am the third editor, replacing Dorothy Wylie, whose profile is included in this edition on page 42. Dorothy, in turn assumed the editorship when Jan Dick, whose foresight led to the creation of the journal, was obliged to give it up for health reasons. These two outstanding nursing leaders served as editors for 15 years between them. That in itself is intimidating. They established a proud tradition, and I am honoured to be in a position to carry it on.

This issue represents a significant step in the evolution of the Canadian Journal of Nursing Leadership (CJNL). For the first time, the journal has a professional publisher. Longwoods Publishing Corporation has added this journal to the four existing Canadian journals it publishes: Hospital Quarterly, the Longwoods Review, HealthcarePapers and ... we will examine topics related to the politics, policy, theory, and innovations that contribute to leadership in these domains.

ElectronicHealthcare. Adding a Canadian nursingfocused, leadership-oriented journal to these titles provides a well-rounded repertoire of Canadian journals that bring information as well as wide-ranging debate to topics that are highly relevant to healthcare providers and administrators. It's a partnership that brings the entrepreneurial genius of publisher Anton Hart and a team of editors and designers to the service of this journal. And, it means that I can devote my attention entirely to the content without having to worry about details like budgets, formats, design or covers. This is a very good thing given my knowledge of the latter.

Unlike many scholarly journals, the CJNL serves several audiences. It is the official journal of the Academy of Canadian Nurse Executives (ACEN), the organization of senior nursing administrators in Canada's academic health science centres. However, as the journal of nursing leadership, we are interested in leadership across all of nursing's four domains - administration, practice, teaching and research. And we will examine topics related to the politics, policy, theory and innovations that contribute to leadership in these domains.

As you'll see in these pages, we are testing a new format. There will be five regular columns. The ACEN column will provide ACEN with a forum to communicate information and issues relevant to that organization. The subsequent columns 
will reflect the four nursing domains outlined above. In each issue, invited columnists will be asked to address a theme that spans the four areas. To kick things off, in this issue our columnists, who are acknowledged leaders in their respective fields, were asked "What is Leadership?" You will see that they have tackled this topic in quite different ways, some highly personal and others more objective. The variety in these columns is refreshing and offers thought-provoking insights.

\section{... it is important to bring sound appraisal skills and excellent judgment to determine the state of science that underpins the myriad of questions confronting nursing leaders.}

The journal also has a section called "Ideas in Leadership" that features position or discussion papers on topics relevant to our audiences. We are interested in provocative papers that invite discussion and response. These papers will not be peer-reviewed but we will invite and publish commentaries on each piece. Commentaries are not critiques but rather reflections on the topic

as it is presented by the authors. Again, I believe we have been exceptionally wellserved by the commentators in this issue.

The next section is "Innovations in Leadership." Innovations are a critical source of information particularly to administrators and practitioners. Facilities, or more usually divisions within facilities, often develop innovative approaches to manage problems and report them in a systematic way. There is rarely a formal evaluation but the information is useful to those who face similar problems and are seeking possible solutions. These will be reviewed for their innovative aspects and for the coherence and clarity of their presentation.

Finally, leadership research is a critically important section of the CJNL and papers in this section will be rigorously peer-reviewed. In this issue there is only one research report, but in future, this section will be expanded to three to five papers. Again, the focus will be on research that is relevant to leadership in the four domains. We anticipate the time when the CJNL is the preferred journal for Canadian researchers on these topics and by researchers internationally because of the high quality of the research that is reported.

In the future, we intend to include a systematic review in each issue. This will provide all of our readers with a critical appraisal and analysis of research in response to a specific question relevant to leadership in one of the domains. As many readers will be aware, the Cochrane Collaboration provides systematic reviews for clinical questions across a wide spectrum of specialty areas. Research relevant to nursing leaders is usually not designed as randomized trials and this implies that a greater degree of judgment is required in interpreting the results across several studies. Nevertheless, it is important to bring sound appraisal skills and excellent judgment to determine the state of science that underpins the myriad of questions confronting nursing leaders. 
Finally, we hope that the CJNL will be the home of lively debates in the form of letters to the editor, editorials, keynote addresses and discussion papers across many contentious issues. Among current journals, the British Medical Journal probably does the best job with this and frequently does it with wonderful humour. Are not Canadians known for their humour? This is an exceptional standard to aim for but let us try.

Perhaps editing this journal is not so different from skydiving. I suspect they both involve the prospect of soaring to great heights, seeing endless possibilities and contemplating how to put it all into words when you return to the ground. Please join me in this adventure to make the Canadian Journal of Nursing Leadership an indispensable resource for all nursing leaders and all those who aspire to leadership.

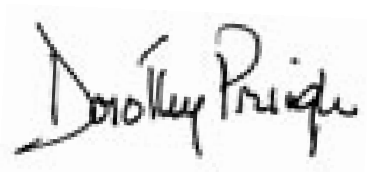

Dorothy Pringle

Editor-in-Chief

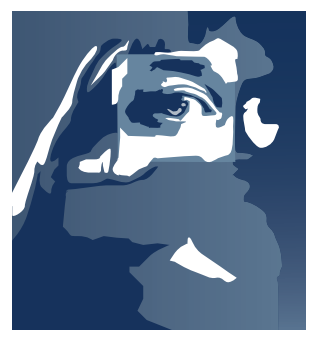

\section{The Critical Eye}

Longwoods is pleased to apply a critical eye to research papers in this journal and our new health services peer-reviewed journal — the Longwoods Review. Research is incomplete until it undergoes review by an investigator's peers, is revised accordingly, and is published. Without a critical eye, we increase the risk that the data and interpretation of a study will be biased or even wrong (NEJM 1995).

We are also a publisher of new models and best practices. We want to see knowledge applied. And so to help establish the value of the research we will, from time to time, apply the discerning and critical eye of leaders. (Harvard Business School Working Knowledge 2001). This provides them the opportunity to consider the meaning and relevance of the research. Can they foresee the outcomes, track progress and measure results? We trust that the value of research we publish will eventually be determined by its contribution to better care.

This concept of the eye logo, conceived by Yvonne Koo, will indicate that the work has been peer reviewed. Rigorously peer-reviewed. That's the meaning of our critical eye.

\section{References}

The New England Journal of Medicine (NEJM). 1995 "Editorial." 332(25).

Harvard Business School Working Knowledge. 2001. Knowledge Management: Four Obstacles to Overcome. Feb 26. 